\title{
LEGACY DATA IN THE MINNESOTA SPRING INVENTORY
}

\section{Gregory Brick}

Minnesota Department of Natural Resources, 500 Lafayette Road, St. Paul, MN 55155 USA, gregory.brick@state.mn.us

\begin{abstract}
Past spring inventories have covered certain parts of Minnesota reasonably well; notably, the springs of the Minneapolis-St. Paul metropolitan area and the southeastern Minnesota karst. But hitherto, there has not been a systematic effort to create a uniform statewide inventory. The first step, before hunting down new springs, was to compile existing data and the most fruitful source of hydrological legacy data for the Minnesota spring inventory was the Department of Natural Resources (DNR) Fisheries files. Once entered into a GIS-capable database, these spring locations can help "seed the ground" so that when crews finally do take to the field to map more springs, they will have known examples to work from. Good baseline and time-series data should also help evaluate the impact of climate change and land use changes on Minnesota's springs over time.
\end{abstract}

\section{Introduction}

Past spring inventories have covered certain parts of Minnesota reasonably well; notably, the springs of the Minneapolis-St. Paul metropolitan area (Brick, 1997) and those of the southeastern Minnesota karst (Gao et al., 2005). There has not been a systematic effort to create a uniform inventory for the rest of the state- $\mathrm{a}$ much larger, glaciated area. In 2014, state funding was provided for starting such a database. The first step was to compile existing data, which turned up in unexpected places, as explained below.

While there have been numerous other spring inventories around the country over the years, the neighboring state of Wisconsin's has been the most relevant for comparison. The Wisconsin Conservation Department (WCD) from 1956 to 1962 mapped more than 10,000 springs in that state, the core of their present survey (Macholl, 2007). Conservation officers, familiar with their own areas, plotted the springs and recorded data such as flow rate and water temperature. Some of the points are not well defined, including features like the proverbial spring-fed lake. Indeed, the word "spring" was not even defined, nor distinguished from a seep. The Wisconsin Geological and Natural History Survey maintains an active research program involving these springs today, building on this earlier foundation (Swanson, 2013).
Setting aside for the moment differences from Wisconsin in climate and geology, and judging strictly by proportionate area, Minnesota should have about 15,000 springs, all else being equal. Even more than that, if you consider that only two-thirds of Wisconsin was covered by the WCD survey.

\section{Minnesota's Karst Features Database}

The southeastern corner of Minnesota already has an existing spring inventory as part of its Karst Features Database (KFDB) which includes 2,648 springs (as of March 15, 2015). As described by Alexander and Tipping (2002):

"Since the early 1980s, the Minnesota Geological Survey and Department of Geology and Geophysics at the University of Minnesota have been mapping karst features and publishing various versions of their results in the form of 1:100,000 scale County Geologic Atlases. In the mid-1990s, the Minnesota Department of Natural Resources was assigned responsibility for the hydrogeology portions of the County Atlases and is now responsible for the karst mapping.... A karst feature database of southeastern Minnesota has been developed that allows sinkhole and other karst feature distributions to be displayed and analyzed across existing county boundaries in a GIS environment. The central DBMS is a relational GIS-based system interacting with three modules: spatial operation, spatial analysis, and hydrogeological modules. Data tables are stored in a Microsoft ACCESS 2000 DBMS and linked to corresponding ArcView shape files... The karst inventory points were features such as sinkholes, springs, and stream sinks extracted from the karst feature database of southeastern Minnesota. Both inventory points and karst feature database are updated on regular basis. This research was supported with funding from the Minnesota Department of Health."

The relational structure of the KFDB involved a total of 15 tables: a top-level karst feature index table, 12 mid-level tables to encompass the 12 entities and two 
bottom-level tables for addresses and remarks (Gao et al., 2005).

\section{Unexpected Trove}

The KFDB notwithstanding, Minnesota's equivalent of the WCD spring survey turned out to be elsewhere in the veritable trove of spring legacy data in the DNR Fisheries files. Springs are important for providing proper habitat for trout and other fishes. By the 1940s stream surveys were conducted for fishable streams ranging from major trout streams, like the Root River, to diminutive, unnamed urban creeks and rural ditches. Among these features there will be found data on springs, including location, estimated flow rate, and temperature, similar to the WCD survey. Duplicates of these forms are archived at the DNR's Central Office in St. Paul, MN where they are filed by county, one stream per manila folder. Major rivers straddling multiple counties, such as the Minnesota and Mississippi rivers, have their own folders (The folder for the Minnesota River valley listed 500 springs where few had been known before). Streams are further identified by their Kittle Code, which identifies the watershed and order of tributaries. The folder also contains a stream management plan, "shocking notes" (the basis of electrofishing population assessments), creel censuses, hand-colored maps, onion-paper correspondence, yellowed newspaper clippings, and so forth. These folders are stored in more than three dozen tightly stuffed drawers of a huge mechanical KARDEX Lektriever (Figure 1). While the latest DNR stream surveys are being made available electronically the vast bulk of spring data can only be manually accessed from these hardcopies. Exact numbers are not yet tallied but the KARDEX "fishing expedition" likely netted several thousand features.

The Stream Survey is divided into many sections, evaluating the fitness of the stream as fish habitat and recording what species were found there. Section 29 covers "Tributaries and Springs." Spring locations are given in terms of miles from the river mouth. GPS coordinates have become more common in the recent stream surveys. For comparison, the stated accuracy of the original WCD survey is one quarter section (Macholl, 2007).

However, different DNR fisheries field offices had different traditions of how to fill out the stream surveys. A striking juxtaposition is provided by neighboring Cook and Lake Counties on the North Shore of Lake Superior. Cook County has an abundance of recorded springs and Lake County, very few. Yet this turned out to be merely a reporting difference, not a real one.
Moreover, the folders will sometimes contain hand sketched maps with spring locations not mentioned in Section 29, so the entire folder for a given stream must be examined (Figure 2). Given the reported decline in spring flow with time (Surber, 1924; Moyle 1947) and given the decades over which these files have been amassed, it is possible that the springs were visible at one time but not another. Or perhaps the record reflects climate change or land use changes over the years.

There are drawbacks to the stream surveys from the perspective of a geologist. Spring classification is rudimentary in the extreme. Some of the more detailoriented surveyors adopted a crude, three-fold scheme, dividing them into bank, bed, and cave springs. Apart from general remarks in the report itself, the geologic context of the springs is entirely lacking. The formation name, lithology, and so forth are not indicated.

The single most valuable find among the DNR stream surveys was a comprehensive 1922 map of the springs of the North Shore drafted on linen, 1.5 meters long, by Thaddeus Surber (1871-1949). Surber wrote an accompanying report for the North Shore (Surber, 1922) in which he points out some hydrologic paradoxes that will be the subject of a future paper by the present author. Surber is best known for his work as an aquatic biologist in southeastern Minnesota, where during his Root River survey of 1918 and 1920 he "traveled afoot along its many branches upwards of a thousand miles" (Surber, 1941). Mel Haugstad (1930-2013), a dedicated DNR

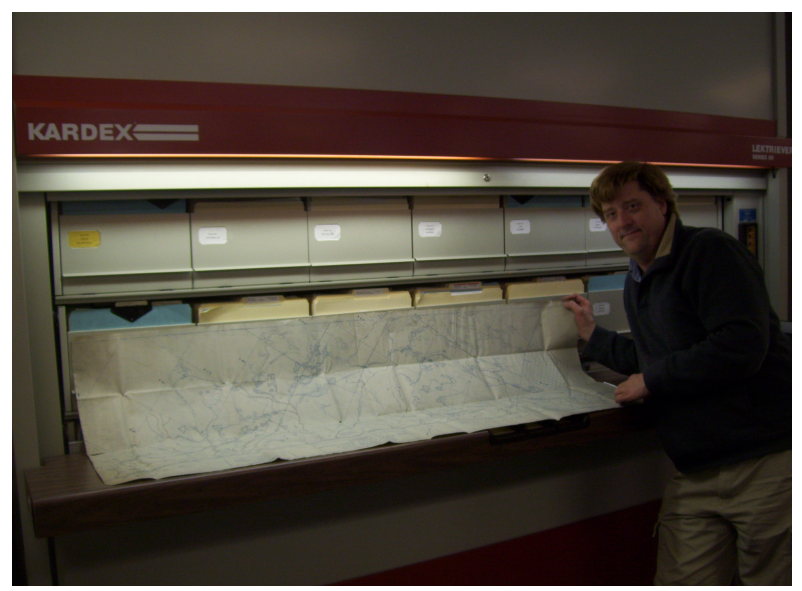

Figure 1. Spring-hunter's delight. KARDEX mechanical file retrieval system atDNR Fisheries, a trove of legacy spring data. Greg Brick shown with the 1922 Surber linen map of North Shore spring locations, a valuable cartographic find hidden among the old stream surveys. 


\section{Crystal creex}

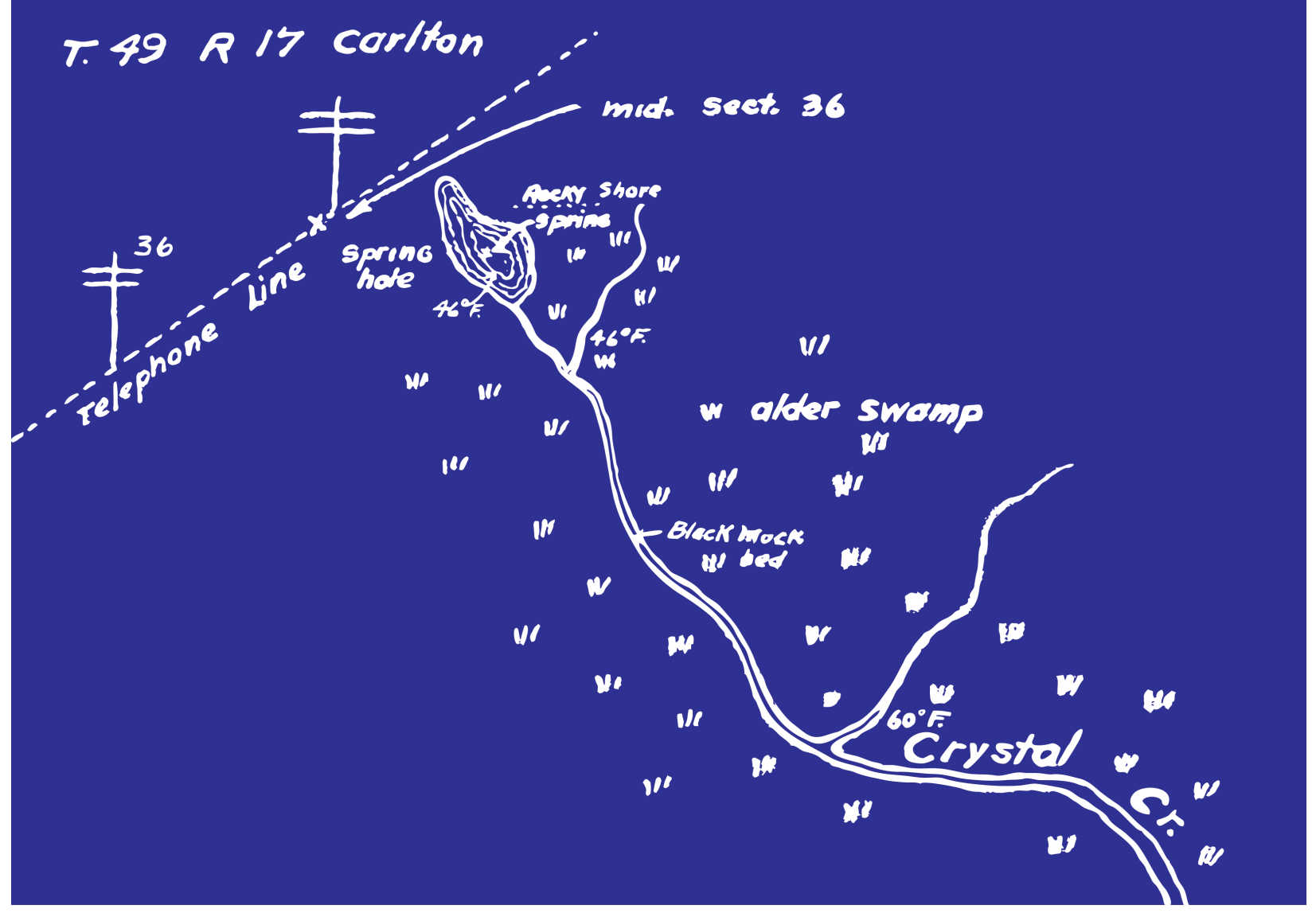

Figure 2. A blueprint showing spring locations in Carlton County, MN, as an example of legacy data. From Surber (1925), image processed by Holly Johnson (DNR).

fisheries manager, hiked the tributaries again adding further details.

The Lanesboro Fish Hatchery, established at Lanesboro, MN in the 1920s, is the repository of Haugstad's legacy data. In a huge project directed by the Minnesota Pollution Control Agency (MPCA) the paper quadrangles with Haugstad's detailed annotations are being scanned to make them more widely available (Broberg and Ignatius, 2015).

In addition to DNR Fisheries another DNR program, the Minnesota Biological Survey, has a database of seepage indicator plants - some of them rare - and lists of "rich" (i.e., groundwater-fed) fens, which harbor mud springs. Many of these are located along the "fenland arc" sweeping up the Minnesota River valley and along the edge of Glacial Lake Agassiz towards the Canadian border.

Another prolific source of legacy spring data was past publications of the Minnesota Geological Survey (MGS), especially the original county geologic reports by Winchell, Upham, and others from 1872 onwards. Here, the most surprising results included the number of cities in drier western Minnesota that were using springs as a municipal water source into the early twentieth century. Many of the standard county histories assembled in the reading room of the Minnesota History Center in St. Paul, have a geology chapter that is often just a reprint of this original MGS report.

The U.S. Geological Survey (USGS), especially its Water-Supply Papers, was consulted, and the Geographic Names Information System (GNIS) maintained by the 
USGS lists 10 named springs for Minnesota quadrangles and many more place names containing the word "spring." Neighboring Wisconsin has 166 named springs listed in GNIS, perhaps because the mappers there chose to identify more of them by name. Once again, we find an illusory geological "fault line" along political boundaries. These sorts of boundaries bedevil attempts to create multi-state karst inventories.
Unfortunately, no simple query in GNIS can extract the much larger number of features simply labeled as springs (without a proper name) on USGS quadrangles.

The National Water Information System (NWIS), also maintained by the USGS, is a large repository of hydrological legacy data from many sources, but has limited and sporadic coverage for 43 springs in

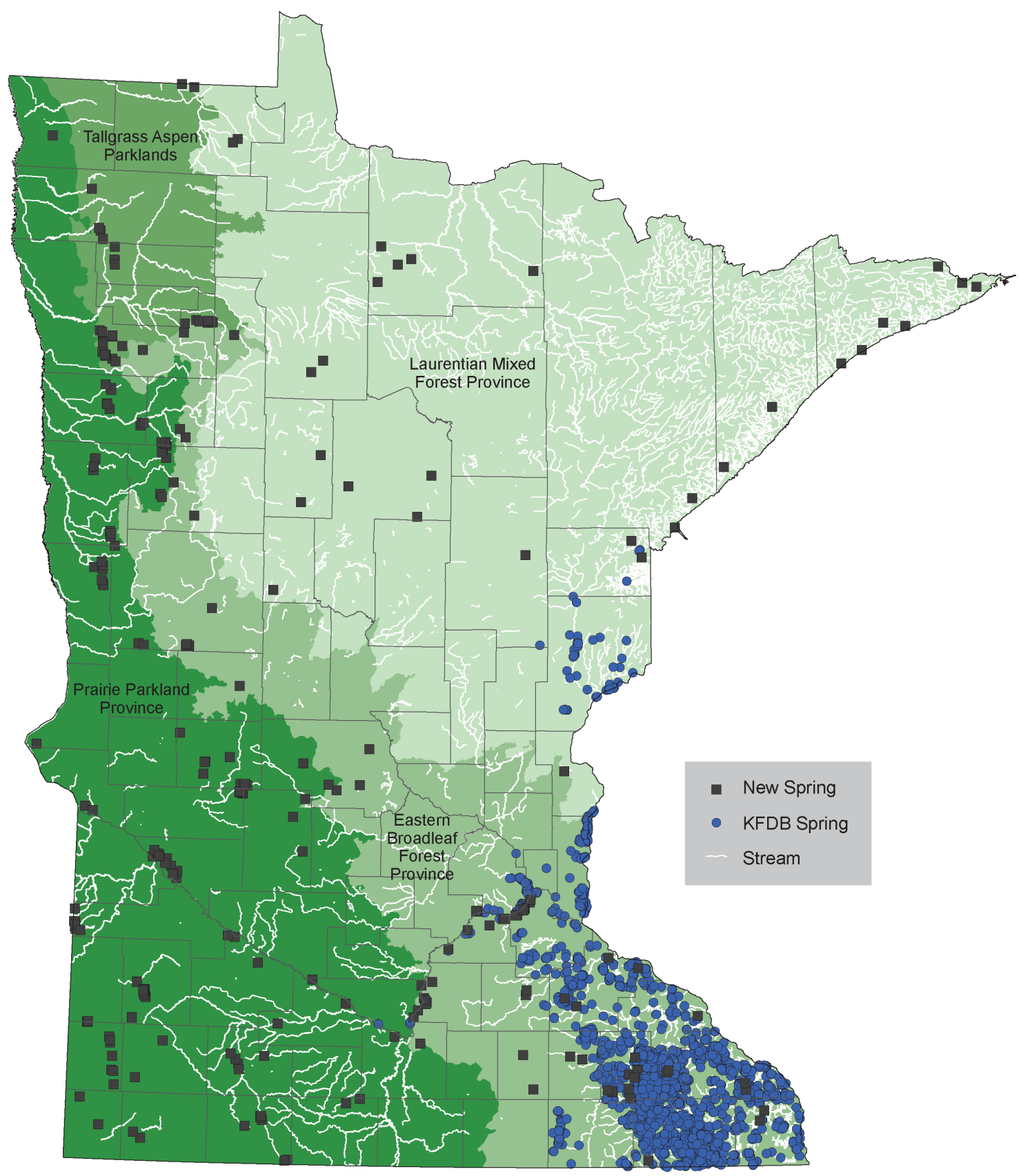

Figure 3. Many "new" legacy spring locations are beginning to populate the map of Minnesota, whereas the KFDB is heavily focused on southeastern Minnesota. Jeff Green and Holly Johnson assisted with map preparation. 
Minnesota; chiefly a cluster in the upper Minnesota River valley and a cluster of brine springs on the Grand Portage Indian Reservation, apparently in support of various USGS investigations. The U.S. Forest Service, especially in the Boundary Waters Canoe Area, has also compiled spring locations.

Combining these sources, the big white space on the map outside of southeastern Minnesota is becoming populated with legacy springs (Figure 3).

\section{Conclusions}

The most fruitful source of hydrological legacy data for the Minnesota spring inventory was the DNR Fisheries files. Before hunting for unmapped springs, it's important to utilize such data. Once entered into a GIS-capable database, these locations can help "seed the ground" so that when crews finally do take to the field to map more springs they will have known examples to work from. Good baseline and time-series data should also help evaluate the impact of climate change and land use changes on Minnesota's springs over time.

\section{Acknowledgements}

Funding for this project was provided by the Minnesota Environment and Natural Resources Trust Fund as recommended by the Legislative-Citizen Commission on Minnesota Resources (LCCMR).

\section{References}

Alexander EC, Jr, Tipping RG. 2002. Karst Features of Minnesota. Available from: http://conservancy. umn.edu/handle/11299/93148.

Brick G. 1997. Along the Great Wall: Mapping the Springs of the Twin Cities. Minnesota Ground Water Association Newsletter 16 (1): 1-7.

Broberg J, Ignatius A. 2015. Value of historic trout stream data in the modern GIS age. Program Abstracts, 8th Annual Driftless Area Symposium; 2015, Feb. 3-4; La Crosse (WI).

Division of Fish and Wildlife, Minnesota Department of Natural Resources. 2006. Fisheries Stream Survey Manual: Stream Survey Methods. Draft Version 2.11.

Gao Y, Alexander EC Jr, Tipping RG. 2005. Karst database development in Minnesota: design and data assembly. Environmental Geology 47: 10721082.

Macholl JA. 2007. Inventory of Wisconsin's springs. Wisconsin Geological and Natural History Survey Open-File Report 2007-03.
Moyle JB. 1947. Farms, springs, and trout: The story of the Root River valley. Conservation Volunteer 10 (58): 1-3.

Surber EW. 1925. Streams and Lakes in or Adjacent to Jay Cooke State Park. Typescript at Minnesota DNR Fisheries.

Surber T. 1922. A Biological Reconnaissance of Streams Tributary to Lake Superior, Baptism River to Devils Track River. Typescript at Minnesota DNR Library.

Surber T. 1924. A Biological Reconnaissance of the Root River Drainage Basin, Southeastern Minnesota. Biennial Report of the State Game and Fish Commissioner of Minnesota for the Period Ending June 30, 1924. Minneapolis: Syndicate Printing Co.

Surber T. 1941. Some early biological surveys on Minnesota waters, 1918-1934. Conservation Volunteer 1 (4): 46-50.

Swanson SK. 2013. Wisconsin's spring resources: An overview. Geoscience Wisconsin 21 (1): 1-13. 
276 NCKRI SYMPOSIUM 5 14TH SINKHOLE CONFERENCE 